experimental conditions becomes an important additional factor affecting their separation and flow characteristics.

Thus, based on the concept of preferential sorption and capillary flow through critical and sub-critical pores. it seems possible to develop a general process for the separation of substances in gaseous, vapour or liquid solutions. It is clear that properly oriented researches on the precise physicochemical criteria of preferential sorption and the development of process techniques for making suitable high flow porous films can contribute much to the emergence of a new and versatile field of separation technology.

Division of Applied Chemistry,

S. SOURIRAJAN

National Research Council, Ottawa.

1 Barrer, R. M., Diffusion In and Through Solids, Chaps. 9 and 10 (Camb. Univ. Press, London, 1951)

2 Kammermeyer, K., Technique of Organic Chemistry, 3, Part 1, 37 (Interscience, New York, 1956).

${ }^{3}$ Choo, C. Y., Advances in Petroleum Chemistry and Refining, 6, Chapter 2 (Interscience, New York, 1962).

- Brown, W. E., and Tuwiner, S. B., Diffusion and Membrane Technology, Chap. 12 (Reinhold, New York, 1962).

${ }^{3}$ Sourirajan, S., Indust. Eng. Chem. Fundamentals, 2, 51 (1963).

- Brubaker, D. W., and Kammermeyer, K., Anal. Chem., 25, 424 (1953); Indust. Eng. Chem., 45, 1148 (1953)

${ }^{7}$ Van Amerongen, G. J., J. Polymer Sci., 5, 307 (1950).

' Weller, S., and Steiner, W. A., J. App. Phys., 21, 279 (1950).

- Brubaker, D. W., and Kammermeyer, K., Indust. Eng. Chem., 46, 733 (1954).

${ }^{10}$ Brubaker, D. W., and Kammermeyer, K., Proc. Conf. Nuclear Engineering, F9-F28 (Univ California, Berkeley, 1953).

11 Rutz, L. O., and Kammermeyer, K., $A E C U-3921$ (1958), and $A E C U$. 4328 (1959), U.S. Atomic Energy Commission, Technical Information Service, Oak Ridge, Tenn.

${ }^{12}$ Kammermeyer, K., and Wyrick, D. D., Indust. Eng. Chem., 50, 1309 (1958).

\section{Calculation of Valence State Energies from Thermochemical Data}

THE predictive power inherent in the concept of intrinsic bond energies has led to many attempts to calculate the energy of the hypothetical valence state of an atom in a molecule ${ }^{1-7}$. The intrinsic bond energy $I$ can be defined ${ }^{1}$ by the equation:

$$
\Delta H_{f}=\Sigma V-\Sigma I
$$

where $\Delta H_{f}$ is the atomic heat of formation of a molecule, $V$ is the energy of the valence state of an atom, and the summation is over all atoms and bonds in the molecule. The valence state of an atom in a molecule can be defined as the hypothetical state in which the free atom would find itself if the bond involved were broken without any change in the electronic configuration of the atom. Long has summarized the attempt to calculate the valence state energy of the tetrahedral carbon atom from thermochemical data ${ }^{1}$. He concluded that the probable limits for the energy of this state are approximately 60-70 kcal/ mole. This value is quoted ${ }^{6}$ as the only experimental value presently available for this quantity. (In several communications with people in this field it has been brought to our attention that this number is still widely quoted.)

One of the primary purposes of this communication is to point out that the limits for the valence state energy of the tetrahedral carbon atom given by Long were based on a value for the heat of atomization of graphite that is no longer accepted. Whereas Long used a value of $125 \mathrm{kcal} /$ mole, it is now known that the heat of atomization of graphite is $171 \mathrm{kcal} / \mathrm{mole}^{8-10}$. Long himself stated that if the controversy over the value for the latter atomization energy were resolved in favour of the higher quantity, then his conclusions were invalid. As often happens in science these qualifications have been commonly ignored when the value of $60-70 \mathrm{kcal} / \mathrm{mole}$ is quoted for the tetrahedral valence state energy of the carbon atom. If Long's procedure is applied with atomic heats of formation based on presently accepted thermochemical data the lower limit becomes 6.8 and $0.8 \mathrm{kcal} / \mathrm{mole}$ instead of the previously reported 58.6 and $48.4 \mathrm{kcal} / \mathrm{mole}$.

It is instructive to consider why Long's valence state energies become trivial when correct values for the thermochemical data are inserted in his procedure. He used equation 1 to set up simultaneous equations of the type:

$$
\begin{aligned}
& \Delta H_{f}, \mathrm{CH}_{\mathrm{s}}=V-4 I \\
& \Delta H_{f}, \mathrm{CH}_{3}=V-3 I
\end{aligned}
$$

based on the assumption that the valence state energies and intrinsic bond energies were essentially equivalent for $\mathrm{CH}_{4}$ and $\mathrm{CH}_{3}$. This is apparently unjustified. In point of fact the bond distances in $\mathrm{CH}_{4}$ and $\mathrm{CH}_{3}$ are 1.094 (ref. 8) and $1.066 \AA$ (ref. 11), respectively, indicating that the $\mathrm{C}-\mathrm{H}$ bond in $\mathrm{CH}_{3}$ is stronger than in methane. This point is also verified by the respective overlap integrals, calculated from Mulliken's tables ${ }^{12}$. The overlap for $s p^{2} \sigma-1 s$ at $1.066 \AA$ is greater than that for $s p^{3} \sigma-1 s$ at $1.094 \AA$; it is believed that $\mathrm{CH}_{3}$ is planar with $s p^{2}$ hybridization of the carbon atom ${ }^{13,14}$. The stronger $\mathrm{C}-\mathrm{H}$ bond in $\mathrm{CH}_{3}$ compared to $\mathrm{CH}_{4}$ requires consideration of appreciably larger intrinsic bond energies for the $\mathrm{CH}_{3}$ molecule, compared to $\mathrm{CH}_{4}$.

Successful application of equation (1) to the calculation of the various valence state energies of carbon from thermochemical data requires either prior knowledge of the intrinsic bond energies, or exact relationships between the intrinsic bond energies in a dissociation sequence such as $\mathrm{CH}_{4}, \mathrm{CH}_{3}, \mathrm{CH}_{2}$ and $\mathrm{CH}$. Such information is not available at present. Actually, the only system that might presently be solved satisfactorily by Long's procedure is that for $\mathrm{BeH}_{2}$ and $\mathrm{BeH}$. Since the ground-state of the beryllium atom has the $2 s^{2}$ electronic configuration, the principle of minimum energy for molecules requires that the beryllium atom in both $\mathrm{BeH}_{2}$ and $\mathrm{BeH}$ be essentially $s p$ hybridized, assuming that these molecules are mostly covalent. For the latter reason the intrinsic bond energies in both of these hydrides should be essentially equivalent, and $V$ identical for the $s p$ beryllium atom in both molecules, since the valence state energy is based on isolated atoms. One can then solve the following equa. tions to obtain $V$ and $I$.

$$
\begin{aligned}
\Delta H_{f}, \mathrm{BeH}_{\mathrm{z}} & =V-2 I \\
\Delta H_{f}, \mathrm{BeH} & =V-I
\end{aligned}
$$

Unfortunately the atomic heat of formation for $\mathrm{BeH}_{2}$ has not been experimentally determined. Using an empirically estimated value of $-153 \pm 3.5 \mathrm{kcal} / \mathrm{mole}$ (ref. 15) for this quantity with $-53 \pm 7 \mathrm{kcal} / \mathrm{mole}$ for $\mathrm{BeH}$ (refs. 8, 16) leads to $V=47+17 \mathrm{kcal} / \mathrm{mole}$ and $I=100 \pm 10.5 \mathrm{kcal} / \mathrm{mole}$. Better values for these energy quantities can be obtained only when better thermochemical data are available.

\section{IEGEL}

Laboratories Division, SEYMour SiEget

Aerospace Corporation,

$$
\text { El Segundo, }
$$

California.

${ }^{1}$ Long, I. H., Experientia, 7, 195 (1951).

${ }^{2}$ Voge, H. H., J. Chem. Phys., 16, 984 (1948); 4, 581 (1936).

${ }^{3}$ Moffit, W., Proc. Roy. Soc., A, 202, 534 (1950).

${ }^{4}$ Ellison, F. O., J. Chem. Phys., 36, 3107 (1962).

${ }^{5}$ Opik, U., Mol. Phys., 4, 505 (1961).

- Wilmhurst, J. K., J. Chem. Phys., 30, 889 (1959).

'Pauling, L., Proc. U.S. Nat. Acad. Sci., 35, 229 (1949).

${ }^{8}$ Cottrell, T. L. Strengths of Chemical Bonds, second ed. (Butterworths Sci. Pub., London, 1958).

Selected Values of Chemical Thermodynamic Properties, Circ. 500, U.S. Nat. Bur. Stand. (Washington, 1942).

${ }^{10}$ Brewer, L., and Searcey, A. W., Ann. Rev. Phys. Chem., 7, 259 (1956).

${ }^{11}$ Wilkinson, P. G., J. Mol. Spect., 6, 1 (1961).

${ }^{12}$ Mulliken, R. S., et al., J. Chem. Phys., 17, 1248 (1949).

${ }^{13}$ Herzberg, G., and Shoosmith, J., Canad. J. Phys., 34, 523 (1956).

${ }^{14}$ Higuchi, J., J. Chem. Phys., 28, 527 (1958).

${ }^{15}$ Obrien, C. J., et al., in Kinetics, Equilibria and Performance of High Temperature Systems, edit. by Bahn, G. S., and Zuckowsky, E., 5-17 (Butterworths Sci. Pub., London, 1960). ${ }^{18}$ Heraberg, G., Spectra of Diatomic Molecules (Van Nostrand Co., New
York, 1950). 